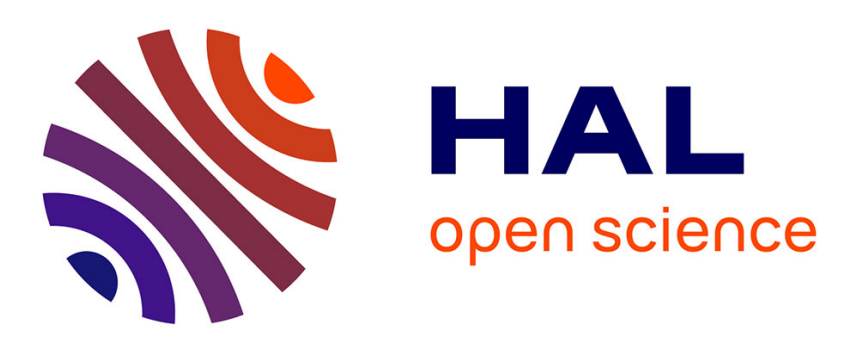

\title{
Assessment of discretization schemes applied to the transport of a passive scalar in a ventilated enclosure
}

Georges Halim Atallah, Emmanuel Belut, Sullivan Lechêne, Benoît Trouette, Stéphane Vincent

\section{- To cite this version:}

Georges Halim Atallah, Emmanuel Belut, Sullivan Lechêne, Benoît Trouette, Stéphane Vincent. Assessment of discretization schemes applied to the transport of a passive scalar in a ventilated enclosure. 19th International Conference on Numerical Analysis and Applied Mathematics ICNAAM, Sep 2019, Rhodes, Greece. hal-02657733

\section{HAL Id: hal-02657733 https://hal.science/hal-02657733}

Submitted on 4 Sep 2020

HAL is a multi-disciplinary open access archive for the deposit and dissemination of scientific research documents, whether they are published or not. The documents may come from teaching and research institutions in France or abroad, or from public or private research centers.
L'archive ouverte pluridisciplinaire HAL, est destinée au dépôt et à la diffusion de documents scientifiques de niveau recherche, publiés ou non, émanant des établissements d'enseignement et de recherche français ou étrangers, des laboratoires publics ou privés. 


\title{
Assessment of discretization schemes applied to the transport of a passive scalar in a ventilated enclosure
}

\author{
Georges Halim Atallah ${ }^{1,2, a)}$, Emmanuel Belut ${ }^{1}$, Sullivan Lechêne ${ }^{1}$, Benoît Trouette ${ }^{2}$ \\ and Stéphane Vincent ${ }^{2}$
}

\author{
${ }^{1}$ INRS, French National Research and Safety Institute for the Prevention of Occupational Accidents and Diseases, \\ Lab. Aeraulic engineering, Vandouvre, France. \\ ${ }^{2}$ Université Paris-Est, Laboratoire Modélisation et Simulation Multi Echelle, MSME, UMR 8208, CNRS, UPEC, \\ UPEM, F-77454, Marne-la-Vallée, France \\ a) georges.halimatallah@ [inrs.fr,u-pem.fr]
}

\begin{abstract}
This paper is a comparative study of classical spatial discretization schemes applied to an experimental case. Numerical simulations are performed according to large cell Péclet numbers. This should show the limitations of some schemes such as the upwind-difference scheme (numerical diffusion) or the central-difference scheme (overshoot and undershoot) for large cell Péclet number. However, in the case of the transport of tracer gas concentration in a ventilated enclosure, we show here that these kinds of schemes are a priori sufficient.
\end{abstract}

\section{INTRODUCTION}

Operators who handle chemicals work under ventilation protection devices, such as laboratory fume cupboards. Their role is to reduce the risk of inhalation of hazardous vapours through their confinement. Despite this, the confinement of these hazardous fumes has been shown to be broken by disruptive air draughts $[1,2,3,4,5]$. Indeed, these confinement breaks generate leaks of toxic fumes outside these protection devices, exposing the operators to inhalation risks. So it is therefore important to precisely quantify the dynamics of these toxic pollutant leaks.

One approach to achieve this is the use of CFD (Computational Fluid Dynamics) technique. The aim is to compute a solution of the transport equation of a passive scalar (tracer gas) using this technique. Several discretization schemes allow this, some of them giving a different response, more or less accurate, depending on the cell Péclet number of the problem. Simulations also need to be performed at large scale and with a reasonnable computation cost. Whence the need to use large time steps that can, a priori, lead to the failure of the boundedness or conservativeness of the numerical schemes. In this study, several discretization schemes will be evaluated by comparing the numerically computed and experimentally measured air age, which is a criterion for evaluating the efficiency of ventilated enclosure confinement.

\section{EXPERIMENTAL SETUP}

A ventilated enclosure is used to carry out a tracer gas transport experiment. This enclosure is a parallelepiped box of volume $0.128 \mathrm{~m}^{3}$ where air is injected permanently at a flow rate of $40 \mathrm{~L} \cdot \mathrm{min}^{-1}$ through a $4 \mathrm{~cm}$ diameter circular inlet and evacuated through an outlet of the same dimension. This results in an air jet with an inlet-based Reynolds number of 1500 (the experiment is described in detail in [6]). After the airflow has become statistically established inside the enclosure, tracer gas is then injected. Its concentration is then measured over time using PID (photoionization detector, Ion Science Ltd) sensors in various locations inside the enclosure. The associated Peclet number varies between 500 and 2000 outside the jet area and between 10,000 and 20,000 inside. The concentration is therefore transported largely by the advection process. 


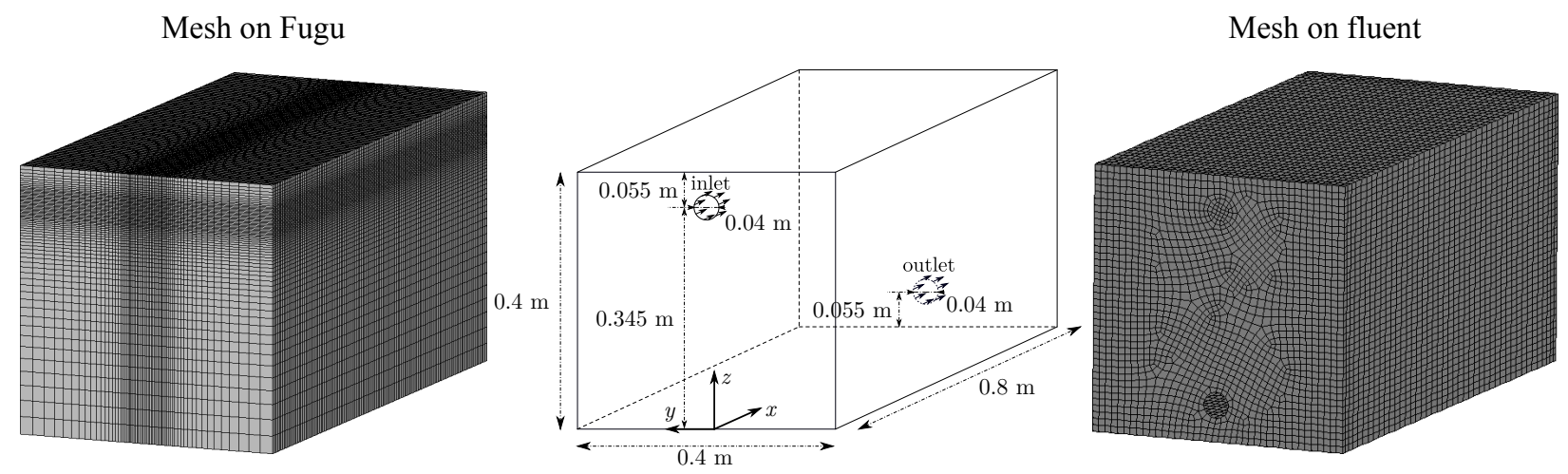

FIGURE 1. Illustration of the ventilated enclosure.

\section{CFD METHOD}

In order to extend the comparisons between the available discretization schemes, two different CFD codes were used for the numerical simulations, the ANSYS FLUENT commercial code and the Fugu homemade code. The QUICK discretization scheme was used in the simulations with ANsys FluENT and the first order upwind-difference, centraldifference and weno schemes type with Fugu. The WALE large eddy simulation model and a direct numerical simulation were used respectively with Ansys Fluent and Fugu. The governing equations of the carrier airflow assumed to be incompressible and isothermal are solved using a finite volume method on an irregular and staggered Cartesian grid with Fugu and a hexahedral grid with Ansys Fluent:

$$
\begin{aligned}
\nabla \cdot \mathbf{u} & =0, \\
\rho\left(\frac{\partial \mathbf{u}}{\partial t}+\nabla \cdot(\mathbf{u} \otimes \mathbf{u})\right) & =-\nabla p+\nabla \cdot\left[\left(\mu+\mu_{\mathrm{sgs}}\right)\left(\nabla \mathbf{u}+(\nabla \mathbf{u})^{T}\right)\right],
\end{aligned}
$$

where $\mathbf{u}$ is the velocity vector, $p$ is the pressure, $\rho \approx 1.225 \mathrm{~kg} \cdot \mathrm{m}^{-3}$ is the density and $\mu \approx 1.789 \cdot 10^{-5} \mathrm{~kg} \cdot \mathrm{m}^{-1} \cdot \mathrm{s}^{-1}$ is the dynamic viscosity of the carrier airflow and $\mu_{\mathrm{sgs}}$ is not zero when a subgrid scale large eddy simulation model is used. Gravity effect are neglected and boundary conditions for $\mathbf{u}$ are no-slip condition for all walls and zero gradient at the outlet for the normal component. A centered scheme is used to discretize the advection term and viscous terms whereas time integration is carried out with a second order Gear scheme. Pressure is obtained by using a time-splitting approach for handling pressure-velocity coupling. A scalar projection method is considered here [7]. These schemes are combined with the preconditioned MILU-BICGSTAB II solver to build a solution of equations (1)-(2). Assuming that the airflow is correctly resolved and statistically converged [8], the equation of advection-diffusion transport of a passive scalar (concentration) is solved consecutively:

$$
\frac{\partial C}{\partial t}+\nabla \cdot(\mathbf{u} C)=\nabla \cdot\left(\left(D+D_{\mathrm{sgs}}\right) \nabla C\right) .
$$

where $C$ is the normalized (from 0 to 1 ) concentration passive scalar of the tracer gas injected into the ventilated enclosure. $D$ is its diffusion coefficient taken equal to $10^{-5} \mathrm{~m}^{2} \cdot \mathrm{s}^{-1}$ so that $D \approx \mu / \rho$ and $D_{\mathrm{sgs}}$ is not zero when a subgrid scale large eddy simulation model is used.

\section{Discretization schemes}

First Order Upwind-Difference Scheme The first order upwind-difference scheme is the most stable and is unconditionally bounded. This scheme is often used for problems where advection transport is the dominant process. Its weak point, mainly due to the fact that it is a first order accurate scheme, is that it can introduce undesired fictitious diffusion to the computed solutions [9].

Central-Difference Scheme The central differencing scheme, which is second order accurate, can produce more precise results but it is subject to conditions that, if not satisfied, leads for example to non-physical overshoot and un- 
dershoot in computed solutions. These unrealistic physical solutions can occur when the cell Péclet number is greater than 2 and which is defined as $\mathrm{Pe}_{\mathrm{c}}=U \Delta x / D$, where $U$ and $\Delta x$ are characteristic velocity and length respectively [10].

Quick (Quadratic Upstream Interpolation for Convective Kinetics) Scheme The quick scheme is a third order accurate scheme and he is less numerically diffusive than the upwind-difference scheme. However, as well as the central-difference scheme, if it does not satisfy a given boundedness condition $\left(\mathrm{Pe}_{\mathrm{c}}<8 / 3\right)$, non-physical overshoots and undershoots may occur in the resulting numerical solutions [11].

Non-conservative Weno (Weighted Essentially Non-Oscillatory) Scheme One advantage of the nonconservative $^{1}$ Weno scheme is its ability to handle the transport of a scalar with strong discontinuities. They are also very little dissipative [12].

\section{RESULTS AND DISCUSSION}

The evolution of the tracer gas concentration injected into the enclosure is calculated at 36 points (sensors) uniformly distributed throughout the interior.

A comparison between the concentration computed and measured at 3 points near the on the enclosure, with different discretization schemes and codes, is presented in Figure 2.

(a)

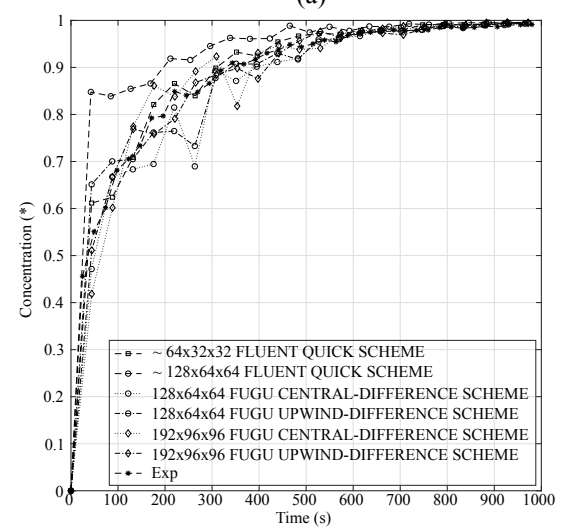

(b)

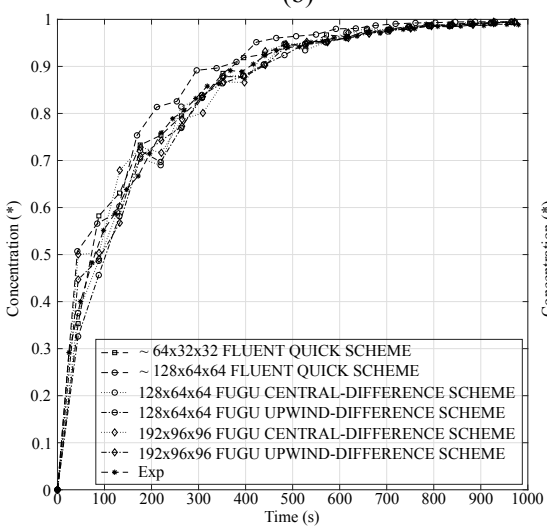

(c)

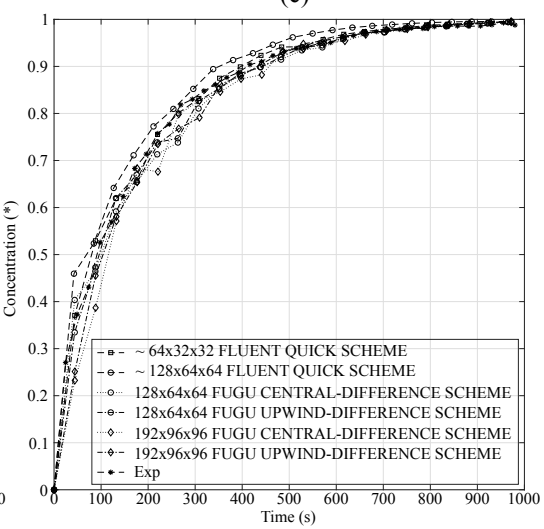

FIGURE 2. Evolution of the tracer gas dimensionless concentration injected into the enclosure at 3 points. The points (sensors) locations are : (a) $\{x=0.3, y=0, z=0.2\} \mathrm{m}$; (b) $\{x=0.5, y=0, z=0.2\} \mathrm{m}$; (c) $\{x=0.7, y=0, z=0.2\} \mathrm{m}$.

The comparison can also be done with an average quantity. This quantity is defined as the mean age of air $\tau_{a}(P)$. It represents the average time required for an air particle to reach a point $P$ in an enclosure, starting from the instant of its introduction. In the case of an injection of tracer gas into an enclosure, the age of the air is calculated according to the following equation:

$$
\tau_{a}(P)=\int_{t_{0}}^{t_{s}} \frac{C\left(P, t_{s}\right)-C(P, t)}{C\left(P, t_{s}\right)-C\left(P, t_{0}\right)} \mathrm{d} t,
$$

with $C\left(P, t_{s}\right)$ the concentration of the tracer gas in a steady state reached regime, $C\left(P, t_{0}\right)$ the concentration of the tracer gas at the time of its introduction and $C(P, t)$ the recorded tracer gas concentration over time at the point $P$.

The comparison of the mean air ages obtained numerically and experimentally for each of the 36 points is presented in Figure 3 with a scatter plot.

\footnotetext{
${ }^{1}$ The term "non-conservative" is used in the meaning of the non-conservative formulation of the solved equation (3) and not in the meaning of a loss or gain of mass.
} 


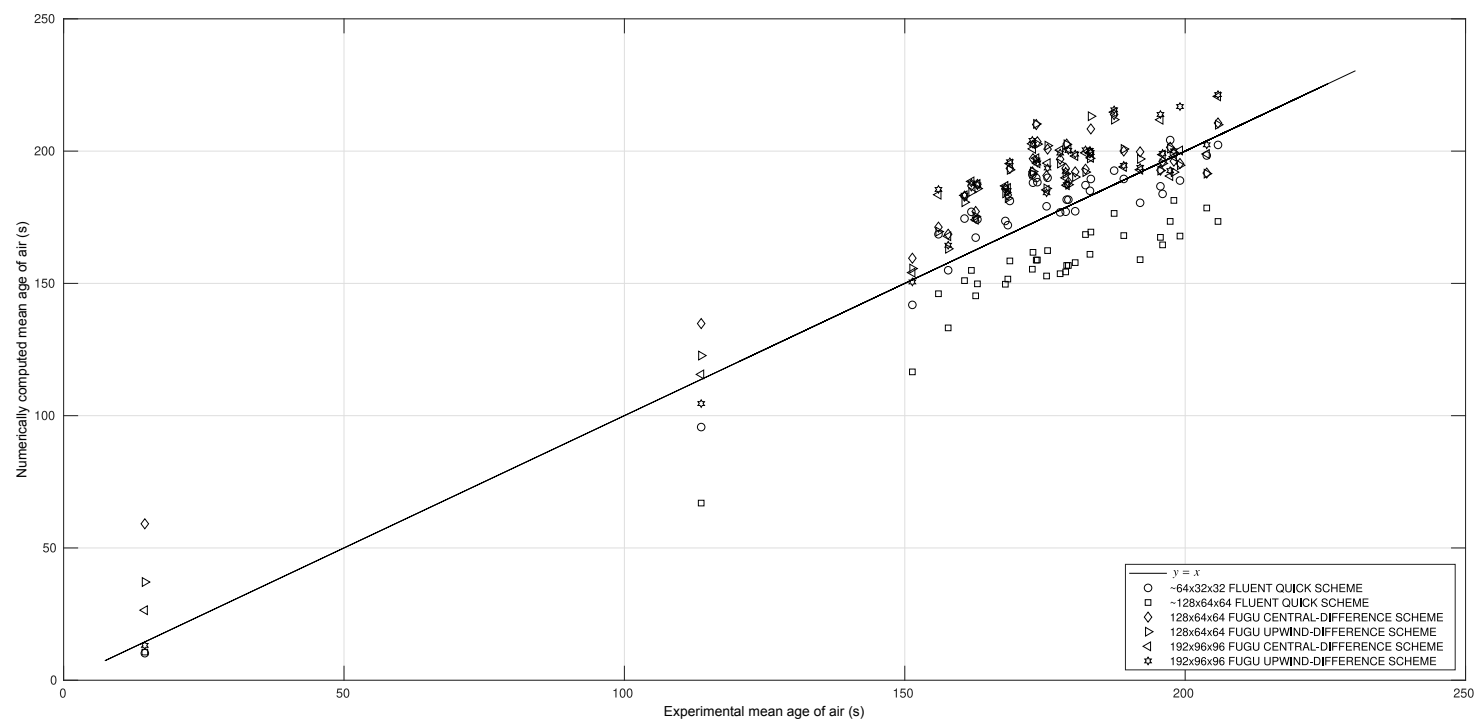

FIGURE 3. Scatter plot of the mean air age computed and measured on the 36 sensors of the enclosure for each simulations.

\section{CONCLUDING REMARKS}

According to the ranges of values of the cell Péclet number which are [125, 1000], [62,500] and [40,333] respectively for mesh sizes $\Delta x$ of $0.8 / 64 \mathrm{~m}, 0.8 / 128 \mathrm{~m}$ and $0.8 / 192 \mathrm{~m}$ with a velocity range of $[0.1,0.8] \mathrm{m} \cdot \mathrm{s}^{-1}$, we would expect that classical spatial discretization schemes would yield results that are not in good agreement with experimental measurements. Despite this, the numerical results show a good agreement with the experimental measurements. The use of higher order discretization schemes, such as weno schemes, which are little dissipative and more suitable for strong scalar discontinuities, but require very expensive computation costs, do not seem necessary. Indeed, it appears that it is the unsteadiness of the flow that helps to restore correct results with classical spatial discretization schemes.

\section{ACKNOWLEDGMENTS}

The authors are grateful for access to the computational facilities of the French CINES (National computing center for higher education) and CCRT (National computing center of CEA) under project number A0032B06115. We are also grateful for I-SITE FUTURE, UPE and PIA under funding ANR-16-IDEX-0003.

\section{REFERENCES}

[1] G. Schuyler, ASHRAE Transactions 428-434 (1990).

[2] A. Johnson and B. Fletcher, Safety Science 24, 51-60 (1996).

[3] L. Tseng, R. Huang, C. Chen, and C. Change, Industrial Health 45, 199-208 (2007).

[4] L. Ekberg and J. Melin, The Annals of Occupational Hygiene 44, 143-150 (2000).

[5] B. Altemose, M. R. Flynn, and J. Sprankle, American Industrial Hygiene Association Journal 59, 321-327 (1998).

[6] R. Guichard and E. Belut, Journal of Aerosol Science 104, 16 - 31 (2017).

[7] K. Goda, Journal of Computational Physics 30, 76 - 95 (1979).

[8] G. Halim Atallah, B. Trouette, E. Belut, S. Vincent, and S. Lechêne, "LES simulation of pollutant transport in ventilation-based mitigation devices," in Turbulence and Interactions TI2018 (Trois Ilets, France, 2018).

[9] S. Patankar, Numerical heat transfer and fluid flow (CRC press, 1980).

[10] H. K. Versteeg and W. Malalasekera, An introduction to computational fluid dynamics: the finite volume method (Pearson education, 2007).

[11] B. Leonard and S. Mokhtari, (1990).

[12] Y. Zhang and C. Shu, in Handbook of Numerical Analysis, Vol. 17 (Elsevier, 2016), pp. 103-122. 